\title{
Prevalence of neuropathic pain and the need for treatment
}

\author{
Pat Morley-Forster MD FRCPC
}

P Morley-Forster. Prevalence of neuropathic pain and the need for treatment. Pain Res Manage 2006;11(Suppl A):5A-10A.

Recent publications have suggested that more than two million adults in the United States suffer from neuropathic pain, but this number seems to be a significant underestimate. The prevalence of neuropathic pain from diabetes and postherpetic neuralgia alone, using the most conservative estimates of incidence, would equal two million Americans. Lesions of the nervous system responsible for pain genesis can occur either in the central or the peripheral nervous system. The most common causes of peripheral neuropathic pain syndromes worldwide are diabetes, HIV infection, cancer-related neuropathy (due to tumour invasion, surgical nerve damage, radiation or chemotherapy-induced nerve damage) and lumbar degenerative disc disease. Other less common, but significant, sources of suffering are postherpetic neuralgia, complex regional pain syndrome, phantom limb pain and postsurgical nerve trauma. Central neuropathic pain can be caused by stroke (infarct or hemorrhage), multiple sclerosis, spinal cord injury and syringomyelia. Certain pain syndromes such as trigeminal neuralgia and vulvodynia, although clearly neuropathic and a source of tremendous suffering, are not discussed in the present article due to space constraints.

There is an unmet need for the treatment of neuropathic pain as evidenced by reports of pain despite the use of opioids and anticonvulsants, continuing psychological difficulties, lack of access to treatments and patients seeking access to complementary therapy.

Key Words: Epidemiology; Neuropathic pain prevalence; Pain, neuropathic

\section{RECOGNIZING NEUROPATHIC PAIN}

The clearest definition of neuropathic pain is "pain due to a primary lesion of the peripheral or central nervous system" (1). It is considered to be distinct in pathophysiology and symptomatology from nociceptive pain, the other broad category of chronic pain. The classic diagnostic hallmarks are the symptom of burning pain and the physical signs of allodynia (commonly touch-evoked pain) and hyperalgesia. Attempts to determine its prevalence have been hampered by controversies around classification and diagnostic criteria. For instance, aching pain does not preclude neuropathic mechanisms and

\section{La prévalence de la douleur neuropathique et le besoin de traitement}

De récentes publications laissent supposer que plus de deux millions d'adultes souffrent de douleur neuropathique aux États-Unis, mais ce nombre semble être grandement sous-évalué. La prévalence de douleur neuropathique causée seulement par le diabète et la névralgie postherpétique, selon les évaluations d'incidence les plus modérées, correspondrait à deux millions d'Américains. Les lésions du système nerveux responsables de la genèse de la douleur peuvent se manifester soit dans le système nerveux central, soit dans le système nerveux périphérique. Les principales causes de syndromes de douleur neuropathique périphérique de par le monde sont le diabète, l'infection au VIH, la neuropathie reliée au cancer (causée par une invasion tumorale, une atteinte chirurgicale des nerfs, la radiation ou une atteinte nerveuse imputable à la chimiothérapie) et une discopathie dégénérative. D'autres sources de douleur moins fréquentes, mais importantes, sont la névralgie postherpétique, l'algoneurodystrophie, les douleurs fantômes des membres et les traumatismes nerveux postchirurgicaux. Les douleurs neuropathiques centrales peuvent être attribuables à un accident vasculaire cérébral (AVC - infarctus ou hémorragie), la sclérose en plaques, un traumatisme médullaire et la syringomyélie. Certains syndromes de douleur, comme la névralgie faciale et la vulvodynie, bien qu'ils soient clairement d'origine neuropathique et la source d'énormes souffrances, ne sont pas abordés dans le présent article pour des raisons d'espace.

Il existe un besoin non satisfait de traiter la douleur neuropathique, nettement démontré par les comptes rendus de douleur malgré le recours aux opiacés et aux anticonvulsivants, ainsi que par les comptes rendus de troubles psychologiques constants, d'absence d'accès aux traitements et de patients cherchant à avoir accès à des thérapies complémentaires. 
The necessity of establishing a classification of pain in neuropathic conditions, which is mechanism-based as opposed to disease-based, has been outlined by Woolf and Max (2). The basic rationale for proposing such a classification is to link treatment strategies to pathophysiological mechanisms expressed clinically as symptoms or signs. For example, many of the clinical features of painful diabetic neuropathy (PDN) are similar in nature to those of postherpetic neuralgia, suggesting overlapping neurophysiological mechanisms. Thus, one drug that targets the basic mechanism of the maladaptive pain, such as opposition of an excitatory neurotransmitter, may be effective in both conditions despite their wide difference in original disease process. Currently, such a classification system, although ultimately a desirable goal, is not yet feasible.

Despite these classification difficulties, there has been substantial progress in determining the prevalence of neuropathic pain in the developed world, and indeed, globally. There has been growing recognition that the condition is associated with serious psychological comorbidities and a high economic burden of care (3). The consequences of undertreated pain are borne not only by the affected individual, but also by society.

\section{DIABETIC NEUROPATHY}

Diabetes mellitus is currently estimated to affect more than 194 million adults in the world, and is expected to affect 333 million by 2025 (4). It is the most common cause of neuropathy in the developed world, with increasing likelihood of development of the complication with longer disease duration, increased age and poorer glycemic control. Pirart (5) published data in 1978 on a cohort of 4400 patients with diabetes followed for 25 years, showing that $45 \%$ to $50 \%$ developed peripheral sensory neuropathy. The Rochester Diabetic Neuropathy Study (6) found an even higher percentage of diabetic patients developed some sort of neuropathy, with a rate of $66 \%$ in insulin-dependent diabetics.

Not all diabetics with neuropathy have pain. Varying diagnostic criteria and differences in grading severity in studies of the prevalence of PDN have led to conflicting results. A large multicentre trial by Zieglar et al $(7)(n=1171)$ determined a prevalence of $11.6 \%$ of PDN in insulin-dependent diabetics with an average duration of nine years, and $32.1 \%$ in noninsulindependent patients with a similar duration (10 years). However, pain was defined by a visual analogue score of greater than $10 \mathrm{~mm}$ on a $100 \mathrm{~mm}$ scale, which is lower than usual criteria. Earlier studies placed the incidence of painful neuropathy in diabetics at approximately $10 \%(8,9)$.

Watson et al (10) showed that diabetics with neuropathy have impaired quality of life in all domains as measured by the Short Form-36 survey instrument, but that these improve with treatment of pain by controlled-release oxycodone. These findings of Short Form-36 scores significantly below the population norm were confirmed by Backonja et al (11) in a randomized, double-blind trial of gabapentin in 162 diabetics with PDN. Galer et al (12) found that in 105 patients with diabetic neuropathy, pain interfered with sleep in $57 \%$ and with mood in $43 \%$.

In summary, taking the most conservative prevalence rate for PDN of $10 \%$, there may be almost 20 million people affected globally, with one-half of these suffering significant impairment in their quality of life. In addition, pain in the feet and legs interferes with walking activity, which is essential to maintain good glycemic control.

\section{HIV INFECTION}

Most recent estimates of the number of HIV case worldwide places the number at 40.3 million people. A review of the epidemiology of neuropathic pain associated with HIV by Verma et al (13) states that neuropathic pain is a common and underrecognized complication of HIV infection. Symmetric polyneuropathy is estimated to occur in more than one-third of HIV-infected patients (14 to 15 million) (14). The proposed mechanism is under debate: one theory postulates direct invasion by the viral glycoprotein; another theory suggests that the increased number of macrophages cause release of neurotoxic cytokines.

Antiretroviral therapy has prolonged lifespan and turned HIV infection from an acute into a chronic illness. The use of dideoxynucleosides in particular has also contributed to painful neuropathy by increasing the incidence of druginduced neurotoxicity clinically indistinguishable from the HIV-caused distal symmetric polyneuropathy. Other types of painful neuropathies associated with HIV include mononeuritis multiplex and progressive polyradiculopathy. Concomitant conditions such as diabetes, alcoholism, vitamin $\mathrm{B}_{12}$ deficiency, anemia and hypoalbuminemia increase the risk of HIVassociated neuropathy (15).

The pain of HIV-associated neuropathy is undertreated even in countries where analgesic medications are prescribed and affordable. The first report examining the incidence of pain and treatment efficacy in a nonselected group of 95 AIDS patients was published by Frich and Borgbjerg (16) from Copenhagen in 2000. Although the overall incidence of painful conditions thought by the patient to be related to AIDS was $88 \%$, pain occurred in the extremities approximately $32 \%$ of the time due to distal symmetric polyneuropathy. Using the Pain Management Index, which compared prescribed analgesics with the patient's self-reported pain intensity, the average Pain Management Index score of -1.6 at study entry indicated inadequate analgesic treatment. Some of the barriers to adequate treatment were identified as patient reluctance to take analgesics for fear of addiction, side effects and not wanting to become tolerant early in the course of their disease. Breitbart et al (17) reported that more than $80 \%$ of patients presenting to a clinic devoted to AIDS-related pain were undertreated, as determined by the patient's self-report of pain intensity.

\section{CANCER-RELATED NEUROPATHY}

The incidence of cancer worldwide is up to seven million patients per year, with at least one-half of all new cases occurring in developing countries (18). Just as with HIV, new treatments are transforming some forms of cancer into a chronic illness rather than one with an inevitably fatal and short course. Although tumour infiltration of nerves is the major cause of neuropathic pain, chemotherapy, radiotherapy and surgical treatments can all induce nerve damage. Painful neuropathy can also be caused by a paraneoplastic disorder. Ironically, the distressing symptoms of neuropathy may become a major source of affliction during their hard-won remission (19). 
How difficult is neuropathic cancer pain to treat? The use of opioids in Denmark to treat cancer and noncancer pain is the highest in the world. Yet of 175 patients with advanced cancer admitted to a specialized palliative care unit in Copenhagen, Denmark, initial pain scores were found to be very high despite that fact that opioids were being prescribed in $81 \%$ of patients. Factors associated with high pain intensity were neuropathic pain, mixed neuropathic/nociceptive pain etiologies and bone metastases. The authors concluded that there was need for improvement in patients with these categories of pain, both through research and recording of treatment outcomes (20).

Lung cancer, the second most common type of cancer, is usually associated with nociceptive pain due to tumour invasion. However, in a meta-analysis of 32 studies, Potter and Higginson (21) found that neuropathic pain accounted for up to $30 \%$ of the total pain experienced by lung cancer patients, with nociceptive pain being the major type of pain in $73 \%$.

Almost 200,000 women in the United States are diagnosed with breast cancer annually; the vast majority must undergo surgery. Recent studies suggest that the incidence of chronic pain following breast cancer surgery may be close to $50 \%$, the vast majority being neuropathic $(22,23)$. This statistic seems alarmingly high, although the incidence of persistent pain does drop over time. One study determined the incidence of pain four years postmastectomy had dropped to $20 \%$ (24). The etiology of postmastectomy pain proposed by Jung et al (22) is all neuropathic and includes phantom breast pain, intercostobrachial neuralgia and neuroma pain, and other nerve injury such as intercostal neuralgia. Other sources of pain are toxicity from chemotherapy, radiation, reconstruction and disease progression.

\section{LOW BACK PAIN}

Low back pain (LBP) is an extremely common problem in the general population, with a lifetime prevalence in adults of $58 \%$ to $84 \%$ and a point prevalence varying from $4.4 \%$ to $33 \%$ (25). Little is published regarding the contribution of neuropathic pain mechanisms to LBP. In their review of LBP, Deyo and Weinstein (26) cited a neuropathic pain incidence of 7\% (ie, only those carrying the diagnosis of herniated disc or spinal stenosis).

The true incidence may be much higher than this if other factors such as peripheral and/or central sensitization of smaller nerve fibres are considered. A multicentre study in Saudi Arabia (27) used The Leeds Assessment of Neuropathic Symptoms and Signs pain scale to differentiate between neuropathic and nociceptive pain. This 24-point scale elicits from the patient burning descriptors, dysesthetic sensations, allodynia and hyperalgesia. The maximum score possible is 24 , with any score greater than 12 suggesting neuropathic pain.

The authors concluded from their study of 1169 patients, drawn from 117 centres, that $54.7 \%$ of chronic LBP was primarily neuropathic in character. Factors associated with neuropathic pain were increased age, female sex, being tall, Caucasian race, hypertension, diabetes, smoking history and previous back surgery. Although the latter factor has been well accepted to be associated with neuropathic pain due to

\section{P INC, = DO NOT COPY}

scarring of the epidural space, many physicians would only consider LBP with sciatic radiculopathy to be neuropathic, with nociceptive pain being the major type of pain in $73 \%$ of patients.

These findings need to be confirmed in other populations but may contribute ultimately to more efficacious treatment of LBP. The complexity of LBP mandates that any treatment paradigm must also address psychosocial factors to be effective.

\section{POSTSURGICAL NERVE TRAUMA}

Surgery has long been recognized as an important cause of chronic pain (28). One large survey of 5130 patients attending pain clinics in northern England assessed the contribution of surgery at $22.5 \%$, second only to degenerative factors (29). The literature identifies certain surgeries to be more commonly associated with persistent pain, such as thoracotomy, breast surgery, amputations, cholecystectomy and herniorrhaphy. The pain is almost exclusively neuropathic due to injury to specific vulnerable nerves at the surgical site. Perttunen et al (30) found the incidence of post-thoracotomy pain from intercostal neuralgia to be $61 \%$ at one year, with $5 \%$ of these patients experiencing disabling pain. This can usually be identified in the immediate postoperative period by high reported levels of pain and high levels of analgesic consumption.

Macrae and Davies (28) concluded their excellent review of chronic postsurgical pain with this statement, "If chronic post-surgical pain is to be diminished, a shift in attitudes is needed in both research and practice similar to that which revolutionized acute postoperative care".

\section{POSTHERPETIC NEURALGIA}

Almost one million cases of herpes zoster are estimated to occur in the United States annually, with the incidence of persistent postherpetic neuralgia at three months rising to as high as $50 \%$ in those older than 75 years (31). Mauskopf et al (32) reported that postherpetic neuralgia significantly interfered with energy, sleep, social engagement, physical mobility and global quality of life dimensions of the Nottingham Health Profile.

Although commonly used as a clinical model of neuropathic pain for randomized, controlled clinical trials, postherpetic neuralgia actually represents quite a small percentage of the neuropathic pain burden in North America.

\section{COMPLEX REGIONAL PAIN SYNDROME}

In 1994, the International Association for the Study of Pain renamed reflex sympathetic dystrophy as complex regional pain syndrome (CRPS). This describes the clinical picture of intense upper or lower extremity pain out of proportion to the precipitating injury, accompanied by edema, sensory and autonomic changes. This is a devastating and poorly understood complication of peripheral injury, occurring approximately $2 \%$ of the time after wrist fractures. Accurate epidemiological data are difficult to collect due to varying diagnostic criteria (33). In the Olmsted County Epidemiology Project, Sandroni et al (34) discovered a period prevalence of 20.6 per 100,000 . The majority of patients were young (36 to 46 years of age), female and healthy before the injury (35). 
Although approximately one-third of the cases do eventually resolve, and another one-third improve, there are no definitively proven effective treatment strategies and a paucity of randomized clinical trials proving effective treatments (36). In a prospective study of 93 patients with the syndrome (37), $62 \%$ reported their activities of daily living to be significantly impaired. Although the general incidence in the population is quite small, they do represent a large proportion of pain clinic visits because the pain is severe and refractory to most treatments (eg, 15\% of visits to the St Joseph's Health Centre Pain Clinic in southwestern Ontario in 2004 were due to CRPS).

\section{PHANTOM LIMB PAIN}

Phantom limb pain, or pain perceived in the absent body part after amputation, is reported to range between $53 \%$ to $72 \%$ but is incapacitating in somewhat less than $10 \%$ of amputee patients (38). Although almost two dozen studies have specifically attempted to describe the prevalence of phantom pain among amputees, they have been plagued by a high rate of dropouts, deaths and failure to distinguish between stump pain and phantom pain. The major indications for amputation are diabetes and peripheral vascular disease, both of which are increasing in an aging population. Once phantom pain has developed, it is quite refractory to treatment with opioids or anticonvulsants (39).

\section{Poststroke pain}

\section{CENTRAL PAIN}

Central neuropathic pain has been estimated to occur in up to $8 \%$ of patients after a stroke, especially if their deficit involves a sensory disturbance (40). The infarcted area does not necessarily involve the thalamus. Onset of pain can come months to years after the stroke, often leading to misdiagnosis that the pain is nociceptive, originating in the painful body part. Pain descriptors are similar to those of peripheral nociceptive pain such as burning, pricking and lancinating. There are few effective treatments available, although tricyclic antidepressants and anticonvulsants, particularly lamotrigine, have shown some benefit.

\section{Spinal cord injury}

Most studies of chronic pain following spinal cord injury (SCI) indicate a prevalence of approximately $65 \%$, with onethird of those experiencing severe suffering $(41,42)$. It may be even higher depending on the age at which SCI occurs (43). Siddall et al (44) followed a cohort of 100 people with traumatic SCI to determine the prevalence of pain in the first five years after injury. A total of $81 \%$ of patients reported pain: at-level neuropathic pain in $41 \%$ and below-level neuropathic pain in $34 \%$. If pain due to spinal cord trauma occurred early after injury it was likely to persist and be severe. In contrast, chronic musculoskeletal pain was less likely to be severe.

\section{Multiple sclerosis}

Pain is a common accompaniment to multiple sclerosis. Osterberg et al (45) surveyed 364 patients registered in their multiple sclerosis clinic and found that $27.5 \%$ had central pain, including almost $5 \%$ with trigeminal neuralgia. Most of the time the pain was severe, occurred daily, lasted years and was rated by the patients as a heavy burden (46).

\section{CLINICAL NEED FOR TREATMENT}

Treatment of neuropathic pain is often difficult, with optimal therapy being determined by trial and error. Woolf and Mannion (47) warn that development of more effective therapy can be achieved only if the relation among the etiology, mechanisms and symptoms of neuropathic pain are understood. Antidepressants and anticonvulsants are effective in less than $50 \%$ of the patients $50 \%$ of the time (48). Opioid treatment, previously considered to be ineffective therapy in neuropathic pain, has increasingly gained acceptance $(49,50)$. However, functionality and quality of life often remain low, despite reduction in pain scores by analgesics. In addition, long-term efficacy and safety data of opioids are lacking.

Many studies have documented the high degree of comorbidity between depression and chronic pain disorders, higher than for other chronic medical illnesses. Therefore, sleep disturbance, anxiety and depression must also be addressed for the pain to resolve (51).

Berger et al (52) reviewed a large sample of the United States Health Insurance Claims database that had received two or more medical encounters in 2000 for a "painful neuropathic disorder". They concluded that patients with painful neuropathic disorders were generally in poorer health and had higher health care costs than peers without these conditions. Similar findings were uncovered by Gordon (53), who carefully documented a number of measures of quality of life and consumption of health care resources in 126 participants across Ontario, Quebec and Alberta, undergoing treatment for PDN, postherpetic neuralgia, cervical radiculopathy and chronic postsurgical pain over three months (53). When compared with other age-matched medical populations, their study population was sicker, had a lower quality of life, a greater incidence of anxiety and depression, more sleep problems and used more medical resources. This agreed with findings from Europe and the United States.

Gilron and Bailey (54) examined barriers to treatment of neuropathic pain in patients pursuing enrollment into clinical trials in southeastern Ontario. Almost $75 \%$ of patients had never seen a pain specialist, $25 \%$ had never tried any antineuropathic analgesics and $41 \%$ had never been prescribed opioids. Identified barriers to the appropriate use of opioids for neuropathic pain were both patients' and doctors' fear of side effects and addiction. These concerns have been documented to be high among family doctors and palliative care physicians in Canada, and are probably even higher in the United States (55). Access to pain clinics will continue to be extremely difficult in Canada, so the burden of care for neuropathic pain will remain with the primary care practitioner.

A prospective survey on 180 outpatients with peripheral neuropathy found $43 \%$ used complementary alternative medicine therapies, with $69 \%$ using physician-prescribed treatments concurrently. The most common reason for complementary alternative medicine therapy use was inadequate pain control with prescribed medications (56). 


\section{COPYRIGH PI PIST \\ SUMMARY}

Neuropathic pain is common in diabetes, HIV, cancer and LBP, as well as in a variety of other well-known states such as postherpetic neuralgia, postsurgical, phantom pain and CRPS. There is an unmet clinical need for treatment of neuropathic pain as evidenced by reports of pain despite opioid and anticonvulsant use, persistent psychological difficulties, lack of access to therapies and patients seeking complementary treatments.

\section{REFERENCES}

1. Bennett GJ. Neuropathic pain: A crisis of definition? Anesth Analg 2003;97:619-20.

2. Woolf CJ, Max MB. Mechanism-based pain diagnosis: Issues for analgesic drug development. Anesthesiology 2001;95:241-9.

3. Nicholson B, Verma S. Comorbidities in chronic neuropathic pain. Pain Med 2004;5(Suppl 1):S9-S27.

4. International Diabetes Federation. Diabetes Atlas, 2nd edn. $<$ http://www.eatlas.idf.org/> (Version current at April 20, 2006).

5. Pirart J. [Diabetes mellitus and its degenerative complications: A prospective study of 4,400 patients observed between 1947 and 1973 (2nd part) (author's transl)]. Diabete Metab 1977;3:173-82.

6. Dyck PJ, Kratz KM, Karnes JL, et al. The prevalence by staged severity of various types of diabetic neuropathy, retinopathy, and nephropathy in a population-based cohort: The Rochester Diabetic Neuropathy Study. Neurology 1993;43:817-24. (Erratum in 1993;43:2345)

7. Ziegler D, Gries FA, Spuler M, Lessmann F. The epidemiology of diabetic neuropathy. Diabetic Cardiovascular Autonomic Neuropathy Multicenter Study Group. J Diabetes Complications 1992;6:49-57.

8. Clark CM Jr, Lee DA. Prevention and treatment of the complications of diabetes mellitus. N Engl J Med 1995;331:1210-7. (Erratum in 1995;333:810)

9. Vinik A, Holland MT, Le Beau JM, Liuzzi FJ, Stansberry KB, Colen LB. Diabetic neuropathies. Diabetes Care 1992;15:1926-75.

10. Watson CP, Moulin D, Watt-Watson J, Gordon A, Eisenhoffer J. Controlled-release oxycodone relieves neuroapthic pain: A randomized controlled trial in painful diabetic neuropathy. Pain 2003;105:71-8.

11. Backonja M, Beydoun A, Edwards KR, et al. Gabapentin for the symptomatic treatment of painful neuropathy in patients with diabetes mellitus: A randomized controlled trial. JAMA 1998;280:1831-6.

12. Galer BS, Gianas A, Jensen MP. Painful diabetic polyneuropathy: Epidemiology, pain description and quality of life. Diabetes Res Clin Pract 2000;47:123-8.

13. Verma S, Estanislao L, Simpson D. HIV-associated neuropathic pain: Epidemiology, pathophysiology and management. CNS Drugs 2005;19:325-34.

14. Schiffito G, McDermott M, McArthur J, et al. Incidence of and risk factors for HIV-associated distal sensory polyneuropathy. Neurology 2002;58:1764-8.

15. Luciano CA, Pardo CA, Mc Arthur JC. Recent developments in the HIV neuropathies. Curr Opin Neurol 2003;16:403-9.

16. Frich LM, Borgbjerg FM. Pain and pain treatment in AIDS patients: A longitudinal study. J Pain Sympt Manage 2000;19:339-47.

17. Breitbart W, Rosenfeld BD, Passik SD, et al. The undertreatment of pain in ambulatory AIDS patients. J Pain 1996;65:243-49.

18. Davis MP, Walsh D. Epidemiology of cancer pain and factors influencing poor pain control. Am J Hosp Palliat Care 2004;21:137-42.

19. Forman AD. Peripheral neuropathy and cancer. Curr Oncol Rep 2004;6:20-5

20. Stromgren AS, Groenveld R, Petersen MA, et al. Pain characteristics and treatment outcome for advanced cancer patients during the first week of specialized palliative care. J Pain Symptom Manage 2004;27:104-13.

21. Potter J, Higginson IJ. Pain experienced by lung cancer patients: A review of prevalence, causes and pathophysiology. Lung Cancer 2004;42:247-57.

22. Jung BF, Ahrendt GM, Oaklander AL, Dworkin RH. Neuropathic pain following breast cancer surgery: Proposed classification and research update. Pain 2003;104:1-13.

23. Wallace MS, Wallace AM, Lee J, Dobke MK. Pain after breast surgery: A survey of 282 women. Pain 1996;66:195-205.

24. Ivens D, Hoe AL, Podd TJ, Hamilton CR, Taylor I, Royle GT. Assessment of morbidity from complete axillary dissection. Br J Cancer 1992;66:136-8.

25. Dionne CE. Low back pain. In: Crombie IK, ed. Epidemiology of Pain. Seattle: IASP Press, 1999:284.

26. Deyo RA, Weinstein JN. Low back pain. N Engl J Med 2001;344:363-70.

27. Kaki AM. Identifying neuropathic pain among patients with chronic low back pain: Use of the Leeds assessment of neuropathic symptoms and signs pain scale. Reg Anesth Pain Med 2005;30:422-9.

28. Macrae WA, Davies HT. Chronic post-surgical pain. In: Crombie IK, ed. Epidemiology of Pain. Seattle: IASP Press, 1999:140.

29. Crombie IK, Davies HT, Macrae WA. Cut and thrust: Antecedent surgery and trauma among patients attending a chronic pain clinic. Pain 1998;76:167-71.

30. Perttunen K, Tasmuth T, Kalso E. Chronic pain after thoracic surgery: A follow-up study. Acta Anesthesiol Scand 1999;43:563-7.

31. Schmader KE. Epidemiology and impact on quality of life of post-herpetic neuralgia and painful diabetic neuropathy. Clin J Pain 2002;18:350-54.

32. Mauskopf J, Austin R, Dix L, Berzon R. The Nottingham Health Profile as a measure of quality of life in zoster patients: Convergent and discriminant validity. Qual Life Res 1994;3:431-5.

33. Galer BS, Bruehl S, Harden RN. IASP diagnostic criteria for complex regional pain syndrome: A preliminary empirical validation study. Clin J Pain 1998;14:48-54.

34. Sandroni P, Benrud-Larson LM, McClelland RL, Low PA. Complex regional pain syndrome type 1 : Incidence and prevalence in Olmsted County, a population-based study. Pain 2003;103:199-207.

35. Ghai B, Dureja GP. Complex regional pain syndrome: A review. J Postgrad Med 2004:50:300-7.

36. Kingery WS. A critical review of controlled clinical trials for peripheral neuropathic pain and complex regional pain syndromes. Pain 1997;73:123-39.

37. Geertzen JH, Dijkstra PU, van Sonderen EL, et al. Relationship between impairments, disability and handicap in reflex sympathetic dystrophy patients: A long-term follow-up study. Clin Rehabil 1998;12:405-12.

38. Kalaukalani DA, Loeser JD. Phantom Limb Pain. In: Crombie IK, ed. Epidemiology of Pain. Seattle: IASP Press, 1999.

39. Jensen T, Nikolajsen L. Phantom pain and other phenomena after amputation. In: Wall PD, Melzack R, eds. Textbook of Pain. 4th edn. Edinburgh: Churchill Livingstone, 1999:808.

40. Hansson P. Post-stroke pain case study: Clinical characteristics, therapeutic options and long-term follow-up. Eur J Neurol 2004;11(Suppl 1):22-30.

41. Siddall PJ, Taylor DA, Mclelland JM, Rutkowski SB, Cousins MJ. Pain report and the relationship of pain to physical factors in the first six months following spinal cord injury. Pain 1999;81:187-97.

42. Bonica JJ. History of pain concepts and pain therapy. Mt Sinai J Med 1991;58:191-202.

43. Werhagen L, Budh CN, Hultling C, Molander C. Neuropathic pain after traumatic spinal cord injury--relations to gender, spinal level, completeness, and age at the time of injury. Spinal Cord 2004:42:665-73.

44. Siddall PJ, McClelland JM, Rutkowski SB, Cousins MJ. A longitudinal study of the prevalence and characteristics of pain in the first 5 years following spinal cord injury. Pain 2003;103:249-57. 
45. Osterberg A, Boivie J, Thuomas K-A. Central pain in multiple sclerosis-prealence and clinical characteristics. Eur J Pain 2005;9:531-42.

46. Ehde DM, Gibbon LE, Chwastiak L, Bombardier CH, Sullivan MD, Kraft $\mathrm{GH}$. Chronic pain in a large community sample of persons with multiple sclerosis. Mult Scler 2003;9:605-11.

47. Woolf CJ, Mannion RJ. Neuropathic pain: Aetiology, symptoms, mechanism, and management. Lancet 1999;353:1959-64.

48. Sindrup HJ, Jensen TS. Efficay of pharmacological treatments of neuropathic pain: An update and effect related to mechanism of drug action. Pain 1999;83:389-400.

49. Dellemijn P. Are opioids effective in relieving neuropathic pain? Pain 1999;80:451-62.

50. Eisenberg E, McNicol ED, Carr DB. Efficacy and safety of opioid agonists in the treatment of neuropathic pain of nonmalignant origin: Systematic review and meta-analysis of randomized controlled trials. JAMA 2005;293:3043-52.
51. Nicholson B, Verma S. Comorbidities in chronic neuropathic pain. Pain Med 2004;5(Suppl 1):S9-S27.

52. Berger A, Dukes EM, Oster G. Clinical characteristics and economic costs of patients with painful neuropathic disorders. J Pain 2004;5:143-9.

53. Gordon A. Uncovering the hidden burden of neuropathic pain. Satellite Symposium Advances in Neuropathic Pain Management. May14, 2005. Canadian Pain Society Annual Conference, Halifax, Nova Scotia.

54. Gilron I, Bailey J. Trends in opioid use for chronic neuropathic pain: A survey of patients pursuing enrolment in clinical trials. Can J Anesth 2003;50:42-7.

55. Morley-Forster PK, Clark AJ, Speechley M, Moulin DE. Attitudes toward opioid use for chronic pain: A Canadian physician survey. Pain Res Manage 2003;8:189-94.

56. Brunelli B, Gorson KC. The use of complementary and alternative medicines by patients with peripheral neuropathy. J Neurol Sci 2004;218:59-66. 


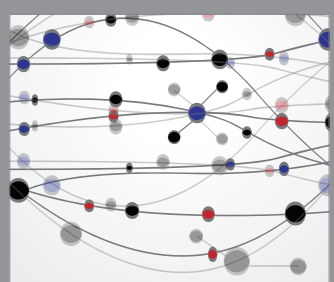

The Scientific World Journal
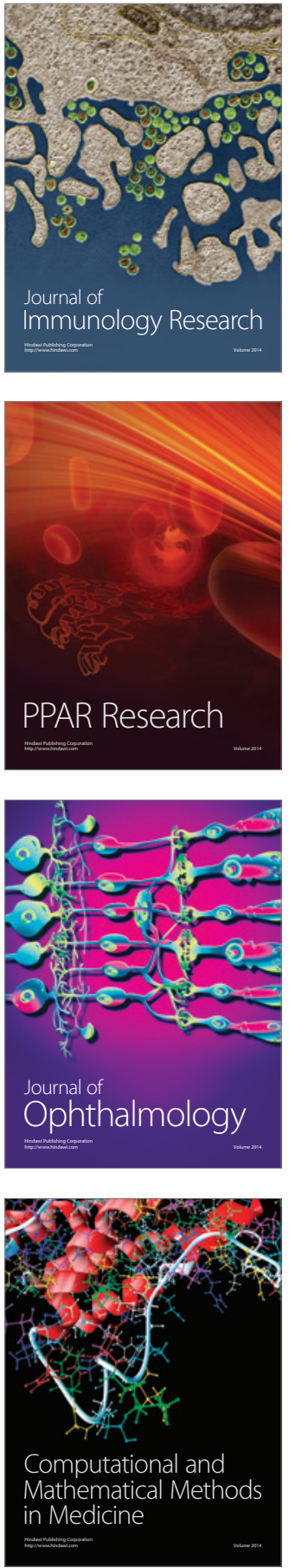

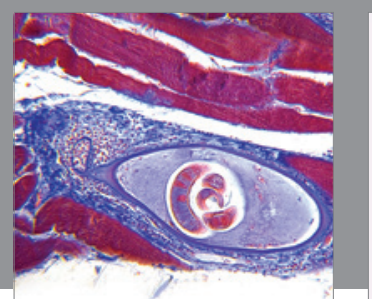

Gastroenterology Research and Practice

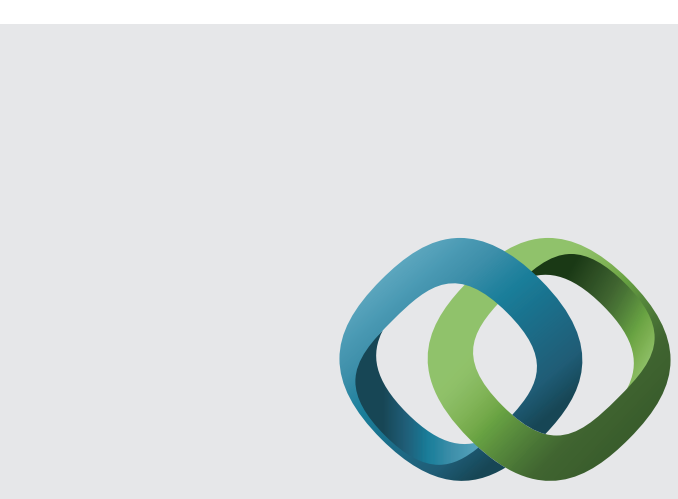

\section{Hindawi}

Submit your manuscripts at

http://www.hindawi.com
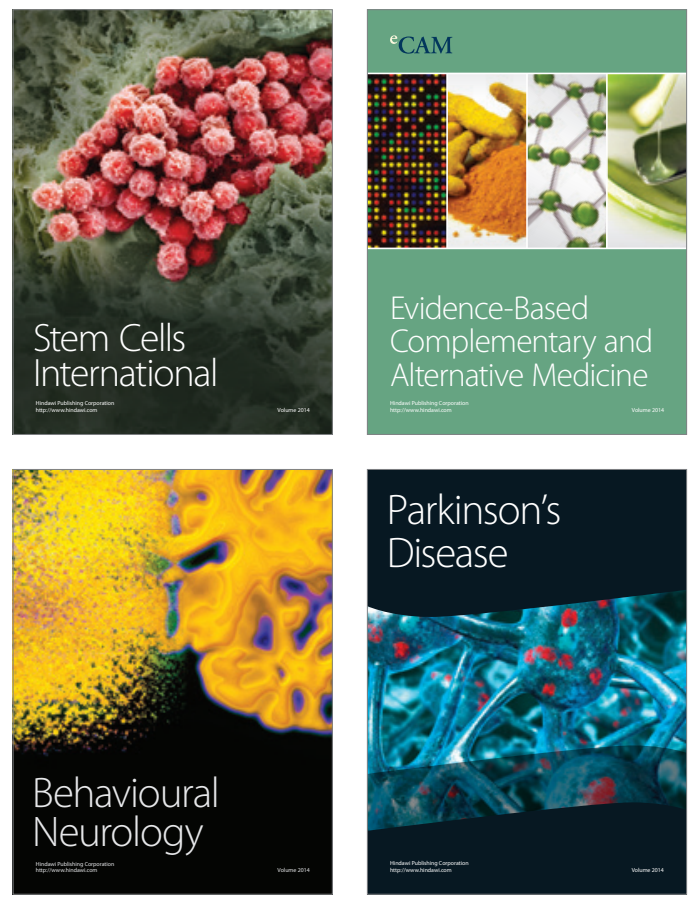
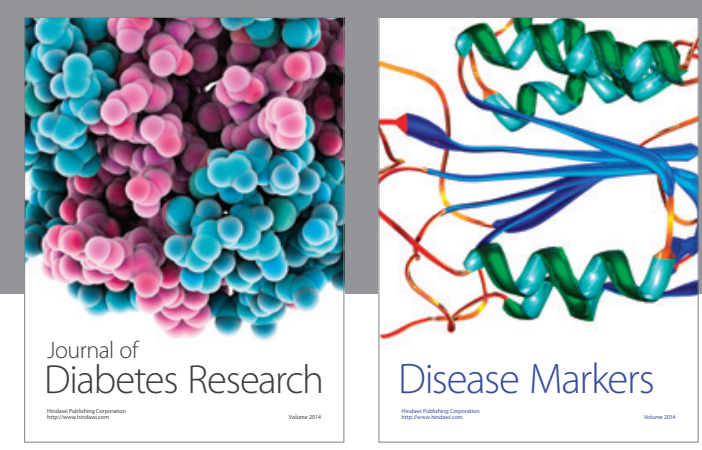

Disease Markers
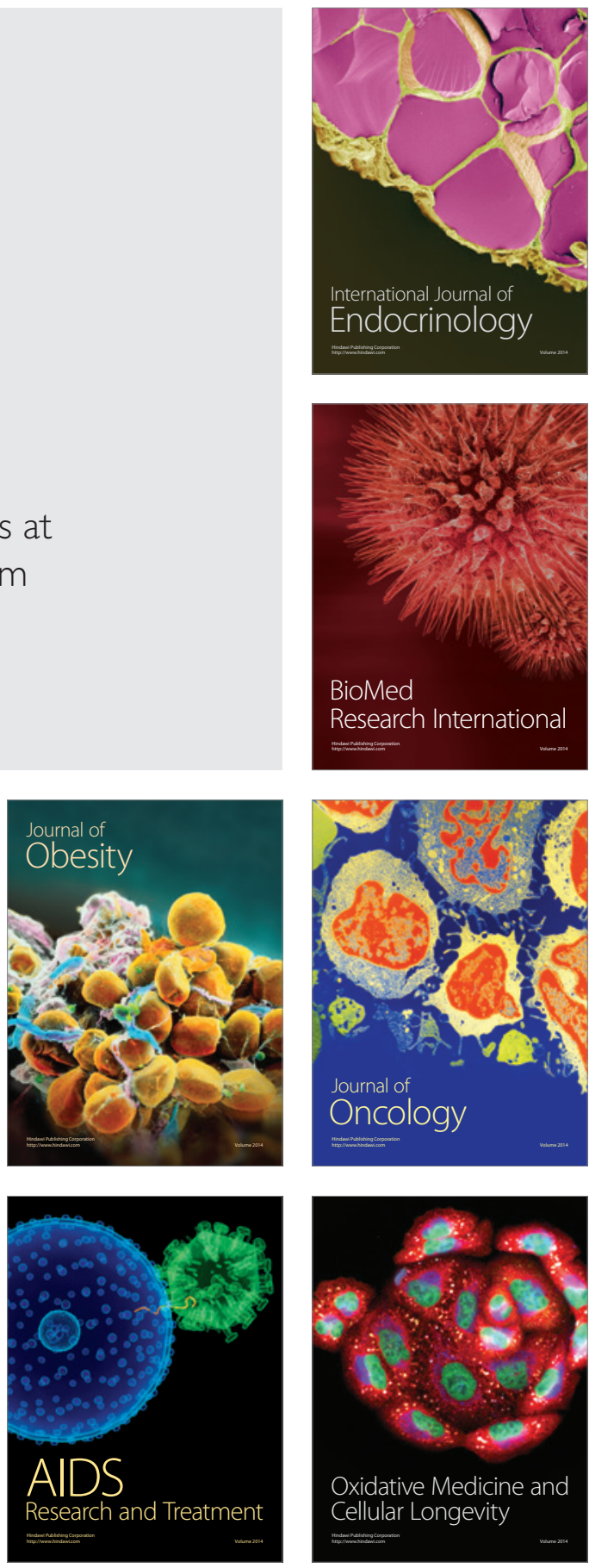